Proceedings of the International Workshop "Oxide Materials for Electronic Engineering" (OMEE-2009), Lviv 2009

\title{
Optical Spectroscopy of the $\mathrm{Nd}^{3+}$ Luminescence Centres in the $\mathrm{Sr}_{4} \mathrm{~B}_{14} \mathrm{O}_{25}: \mathrm{Nd}$ Crystal
}

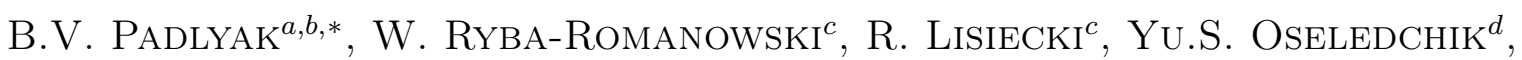 \\ A.L. Prosvirnin ${ }^{d}$, D.P. KudryavtceV ${ }^{d}$ And N.V. Svitanko ${ }^{d}$ \\ ${ }^{a}$ Institute of Physical Optics, 23 Dragomanov Str., 79005 Lviv, Ukraine \\ ${ }^{b}$ University of Zielona Góra, Institute of Physics, Szafrana 4a, 65-516 Zielona Góra, Poland \\ ${ }^{c}$ Institute of Low Temperatures and Structure Research, Polish Academy of Sciences \\ Okólna 2, 50-422 Wrocław, Poland \\ ${ }^{d}$ Zaporizhya State Engineering Academy, 226 Lenin Ave., 69006 Zaporizhya, Ukraine
}

\begin{abstract}
Optical absorption, emission and luminescence kinetics of $\mathrm{Nd}^{3+}$ centres in the new borate crystal with $\mathrm{Sr}_{4} \mathrm{~B}_{14} \mathrm{O}_{25}$ :Nd (Nd content 0.2 wt.\%) composition are investigated and analysed. The oscillator strengths $\left(P_{\text {theor }}\right.$ and $\left.P_{\exp }\right)$ for observed absorption transitions and phenomenological intensity parameters $\Omega_{t}\left(\Omega_{2}=1.59 \times 10^{-20} \mathrm{~cm}^{-1}, \Omega_{4}=2.06 \times 10^{-20} \mathrm{~cm}^{-1}\right.$, and $\Omega_{6}=2.28 \times 10^{-20} \mathrm{~cm}^{-1}$ were calculated based on the standard Judd-Ofelt theory. Using $\Omega_{t}$ parameters the radiative transitions rates $\left(W_{\mathrm{r}}\right)$, branching ratios $(\beta)$ and radiative lifetime $\left(\tau_{\text {rad }}\right)$ for $\mathrm{Nd}^{3+}$ centres in the $\mathrm{Sr}_{4} \mathrm{~B}_{14} \mathrm{O}_{25}: \mathrm{Nd}$ crystal were calculated and analysed. Measured lifetime $\left(\tau_{\exp }=105\right.$ and $93 \mu \mathrm{s}$ at $T=10$ and $300 \mathrm{~K}$, respectively $)$ is compared with this calculated $\left(\tau_{\mathrm{rad}}=331 \mu \mathrm{s}\right)$ and quantum efficiency for $\mathrm{Nd}^{3+}$ centres from ${ }^{4} F_{3 / 2}$ emitting level in the $\mathrm{Sr}_{4} \mathrm{~B}_{14} \mathrm{O}_{25}: \mathrm{Nd}$ crystal is estimated $(\eta \cong 30 \%)$. Incorporation peculiarities and local structure of $\mathrm{Nd}^{3+}$ luminescence centres in the $\mathrm{Sr}_{4} \mathrm{~B}_{14} \mathrm{O}_{25}$ crystal and corresponding glass with $4 \mathrm{SrO}-7 \mathrm{~B}_{2} \mathrm{O}_{3}$ composition are discussed on the basis of referenced X-ray diffraction data and presented results.
\end{abstract}

PACS numbers: 42.70.-a, 78.40.Ha, 78.55.Hx, 78.20.Bh

\section{Introduction}

Borate crystals of various compositions are characterised by interesting non-linear optical, luminescence and laser properties and represent promising materials for different technical applications. In particular, strontium tetraborate crystals are perspective materials for non-linear optics [1-3] and thermally-stimulated luminescence (TSL) dosimetry $[4,5]$ and can be obtained by the Czochralski and Kyropoulos methods. Strontium tetraborates are characterised by excellent optical and mechanical properties such as high UV transmittance (down to about $130 \mathrm{~nm}$ ), high second-harmonic generation (SHG) coefficient and optical damage threshold, high hardness and mechanical strength, non-hygroscopy etc. [1-5]. Photoluminescence and TSL of undoped and doped strontium borate crystals are intensively investigated during recent years [6-10].

Crystals and glasses with different compositions activated by $\mathrm{Nd}^{3+}$ ions are still attractive as active elements for powerful solid-state lasers [11, 12], including lasers with laser emitting diode (LED) pumping [13, 14]. Special interest represents $\mathrm{Nd}^{3+}$-doped acentric crystals as laser and SHG active media simultaneously. Therefore, acentric non-linear crystals activated by $\mathrm{Nd}^{3+}$ are

* corresponding author; e-mail:

B.Padlyak@proton.if.uz.zgora.pl; bohdan@mail.lviv.ua promising materials for self-doubling laser radiation [15]. Investigation of $\mathrm{Nd}^{3+}$ centres with different local environment in disordered crystals and glasses is very important for a complete understanding their spectroscopic and laser properties, because the laser action is possible when the $\mathrm{Nd}^{3+}$ ions are located in specific sites of crystal lattice [16].

Practically all borate compounds can be obtained in both crystalline and glassy states. In the $\mathrm{SrO}-\mathrm{B}_{2} \mathrm{O}_{3}$ system there can be synthesised crystals with $\mathrm{SrB}_{4} \mathrm{O}_{7}$ [1-3] and $\mathrm{Sr}_{3} \mathrm{~B}_{14} \mathrm{O}_{25}$ [17-21] compositions and corresponding glasses with the same compositions [22]. At present time the undoped and rare-earth doped crystals with $\mathrm{Sr}_{4} \mathrm{~B}_{14} \mathrm{O}_{25}$ and glasses with the same $\left(4 \mathrm{SrO}-7 \mathrm{~B}_{2} \mathrm{O}_{3}\right)$ composition of high optical quality were obtained according to [17-19, 22]. Undoped and rare-earth doped $\mathrm{Sr}_{4} \mathrm{~B}_{14} \mathrm{O}_{25}$ crystals represent new perspective laser and SHG materials [20, 21].

The complicated structure of $\mathrm{Sr}_{4} \mathrm{~B}_{14} \mathrm{O}_{25}$ crystals was investigated by different authors $[20,21,23]$. According to $[20,21]$ the structure of $\mathrm{Sr}_{4} \mathrm{~B}_{14} \mathrm{O}_{25}$ crystal belongs to monoclinic system and can be satisfactorily described by the $C 2 / \mathrm{m}$ space group with the following unit cell parameters: $a=16.384 \AA, b=7.72 \AA, c=16.619 \AA$, $\beta=119.8^{\circ}$. There are four Sr, eight $\mathrm{B}$, and sixteen $\mathrm{O}$ atoms in the asymmetric monoclinic unit cell of the $\mathrm{Sr}_{4} \mathrm{~B}_{14} \mathrm{O}_{25}$ compound $[20,21]$. The $\mathrm{B}$ atoms in the $\mathrm{Sr}_{4} \mathrm{~B}_{14} \mathrm{O}_{25}$ crystal exhibit two kinds of hybridisation, $s p^{2}$ and $s p^{3}$, seen in the $\mathrm{BO}_{3}$ triangles and $\mathrm{BO}_{4}$ tetrahedra, respectively $[20,21]$. One $\mathrm{BO}_{3}$ triangle and two $\mathrm{BO}_{4}$ 
tetrahedra are connected to form 6-membered rings that are linked together resulting in the 3-dimensional polymeric network. The Sr cations, located in channels of the polymeric borate anions do not have a well-defined coordination sphere, because $\mathrm{Sr}-\mathrm{O}$ distances are rather widely distributed. Within a range of the $3.1 \AA$ oxygen surroundings include $12 \mathrm{O}$ atoms for $\mathrm{Sr} 1$ and $\mathrm{Sr} 3$ cations, and $7 \mathrm{O}$ atoms for $\mathrm{Sr} 2$ and $\mathrm{Sr} 4$ ones. The Sr-O distances follow in the ranges: 2.481-2.961 (Sr1), 2.434-2.934 (Sr2), 2.435-2.985 (Sr3), and 2.449-2.934 $\AA$ (Sr4). Thus, the $\mathrm{Sr}_{4} \mathrm{~B}_{14} \mathrm{O}_{25}$ structure is characterised by disordered oxygen sublattice, in particular the $\mathrm{O} 1, \mathrm{O} 2$, O4, O7, O8, O11, O13, O15, and O16 atoms are positionally disordered with site occupancy factor close to $50 \%$ $[20,21]$.

According to alternative model [23] the structure of $\mathrm{Sr}_{4} \mathrm{~B}_{14} \mathrm{O}_{25}$ crystals was described by monoclinic $C m c 2_{1}$ space group with following parameters: $a=7.734(5) \AA$, $b=16.332(5) \AA, c=14.556(5) \AA, Z=4.702 \mathrm{~F}(h k l)$, $R=0.078$. The $\mathrm{B}$ atoms in the $\mathrm{Sr}_{4} \mathrm{~B}_{14} \mathrm{O}_{25}$ monoclinic lattice form a 3-dimensional framework consisting of borate groups of two types: three-ring structures $(2 \square$, ) the ring structure which consist of two $\mathrm{BO}_{4}$ tetrahedra (mark as the $2 \square$ ) and one $\mathrm{BO}_{3}$ triangle (mark as $\Delta$ ) (see Ref. [23]). The fraction of 4-coordinate boron ("boron anomaly") $N_{4}=\left[{ }^{4} \mathrm{~B}\right] /\left(\left[{ }^{3} \mathrm{~B}\right]+\left[{ }^{4} \mathrm{~B}\right]\right)$, where $\left[{ }^{3} \mathrm{~B}\right]$ and $\left[{ }^{4} \mathrm{~B}\right]$ are the concentrations of $\mathrm{B}$ atoms with coordination number to oxygen equal to 3 and 4 , respectively. The close $N_{4}$ value for $\mathrm{Sr}_{4} \mathrm{~B}_{14} \mathrm{O}_{25}$ crystal $(\cong 0.5)$ and corresponding glass suggests a structural similarity of the $\mathrm{Sr}_{4} \mathrm{~B}_{14} \mathrm{O}_{25}$ glass and crystal. Layers formed by 14-membered rings are composed of $\mathrm{BO}_{4}$ tetrahedra and $\mathrm{BO}_{3}$ triangles packed within the layer according to herringbone pattern [23]. Four Sr atoms are located under every 14-membered ring. All Sr coordination polyhedra are irregular in shape and their environment is formed by both the $\mathrm{O}$ atoms of neighbouring $\mathrm{B}-\mathrm{O}$ layers and the $\mathrm{O}$ atoms located between the layers. If the coordination sphere is restricted by a distance of $2.85 \AA$, then the coordination numbers of $\mathrm{Sr} 1, \mathrm{Sr} 2, \mathrm{Sr} 3$ and $\mathrm{Sr} 4$ atoms are $6,6,7$, and 6 , respectively. Precise investigations of the $\mathrm{Sr}_{4} \mathrm{~B}_{14} \mathrm{O}_{25}$ crystal structure are in the progress.

From both considered models of the $\mathrm{Sr}_{4} \mathrm{~B}_{14} \mathrm{O}_{25}$ crystal structure $[20,21,23]$ we can conclude that disordering of local structure in these crystals is caused by presence of the several types of $\mathrm{O}^{2-}$ anions, which coordinates different $\mathrm{Sr}^{2+}$ (at least four) and $\mathrm{B}^{3+}$ (at least two) cations in the lattice. That leads to wide distribution of cation-oxygen distances (positional disorder) in the coordinated polyhedra $\left(\mathrm{BO}_{3}\right.$ triangles, $\mathrm{BO}_{4}$ tetrahedra, and different $\mathrm{SrO}_{n}$ polyhedra). So, according to both structure models the disordering of $\mathrm{Sr}_{4} \mathrm{~B}_{14} \mathrm{O}_{25}$ crystals leads to optical multisites of luminescence centres, localised in the cationic ( $\mathrm{Sr}$ and $\mathrm{B}$ ) sites. The analysis of local environment for rare-earth centres in the $\mathrm{Sr}_{4} \mathrm{~B}_{14} \mathrm{O}_{25}$ crystal lattice in the framework of both proposed in $[20,21,23]$ structure models and corresponding glass network is given in Sect. 3.3.
The optical and spectroscopic properties of the Eu-, Pr-, and Nd-doped glasses with $4 \mathrm{SrO}-7 \mathrm{~B}_{2} \mathrm{O}_{3}$ composition were investigated in [22], where it was shown that these impurities are incorporated into the $4 \mathrm{SrO}$ $7 \mathrm{~B}_{2} \mathrm{O}_{3}$ glass network as $\mathrm{Eu}^{3+}, \mathrm{Pr}^{3+}$, and $\mathrm{Nd}^{3+}$ ions and their absorption and emission transitions in the UV-VIS-IR ranges were identified. Preliminary results of optical spectroscopy of the $\mathrm{Nd}^{3+}$ centres in $\mathrm{Sr}_{4} \mathrm{~B}_{4} \mathrm{O}_{25}$ crystals were reported in [24], but up to now their optical and luminescence properties were not systematically investigated and published. The present paper reports growth, structure peculiarities and optical spectroscopy of $\mathrm{Sr}_{4} \mathrm{~B}_{14} \mathrm{O}_{25}: \mathrm{Nd}^{3+}$ crystals. The local structure of $\mathrm{Nd}^{3+}$ luminescence centres in the crystal and glass with $\mathrm{Sr}_{4} \mathrm{~B}_{14} \mathrm{O}_{25}$ (or $4 \mathrm{SrO}-7 \mathrm{~B}_{2} \mathrm{O}_{3}$ ) composition are discussed based on referenced and obtained data.

\section{Experimental details}

The $\mathrm{H}_{3} \mathrm{BO}_{3}$ (boric acid) and $\mathrm{SrCO}_{3}$ (strontium carbonate) chemical compounds of $99.5 \%$ purity were used to grow the $\mathrm{Sr}_{4} \mathrm{~B}_{14} \mathrm{O}_{25}$ : $\mathrm{Nd}$ crystal. The $\mathrm{Nd}$ impurity was added to the crystal composition as $\mathrm{Nd}_{2} \mathrm{O}_{3}$ compound in proportion $\mathrm{Nd}_{2} \mathrm{O}_{3}: \mathrm{SrO}=1: 100$. Starting compounds were ground, mixed, melted and heated up to $1050^{\circ} \mathrm{C}$ for 5-6 h. The Nd-doped $\mathrm{Sr}_{4} \mathrm{~B}_{14} \mathrm{O}_{25}$ crystals were obtained by modified Czochralski method (top seeded solution growth (TSSG) method with pulling) at $1050{ }^{\circ} \mathrm{C}$ using technological conditions developed by authors and described elsewhere [17-19]. Obtained single crystals of approximate $25 \mathrm{~mm}$ in diameter and $10 \mathrm{~mm}$ in length have cylindrical shape faceted partly by the (002) and (110) crystallographic planes.

The basic chemical composition of obtained crystals was controlled by X-ray microanalysis technique using a "Comeka Comebax" apparatus. The $\mathrm{Sr}_{4} \mathrm{~B}_{14} \mathrm{O}_{25}$ :Nd crystals were almost uncoloured. According to inductively coupled plasma (ICP) analysis the content of $\mathrm{Nd}$ impurity in the investigated crystal did not exceed 0.2 wt.\%. Paramagnetic impurities were controlled by electron paramagnetic resonance (EPR) technique. The $\mathrm{Sr}_{4} \mathrm{~B}_{14} \mathrm{O}_{25}$ : Nd crystal of high optical quality without any paramagnetic impurities was selected for optical spectroscopy. Oriented by X-ray diffraction technique sample was cut and polished to approximate size of $a=6, b=3$, and $c=2 \mathrm{~mm}$ and was used for optical measurements, including absorption in the polarised light.

One can notice that the undoped $\mathrm{Sr}_{4} \mathrm{~B}_{14} \mathrm{O}_{25}$ single crystals are transparent in the UV spectral range down to $227 \mathrm{~nm}$ and are characterised by high IR transparency up to $3200 \mathrm{~nm}$ [19-21]. The lowering of UV transmission of the $\mathrm{Sr}_{4} \mathrm{~B}_{14} \mathrm{O}_{25}$ in comparison with $\mathrm{SrB}_{4} \mathrm{O}_{7}$ crystals (down to $135 \mathrm{~nm}$ ) is related to planar triangle boron groups $\left(\mathrm{BO}_{3}\right)$, presented in the $\mathrm{Sr}_{4} \mathrm{~B}_{14} \mathrm{O}_{25}$ structure, besides 3-dimensional tetrahedral $\left(\mathrm{BO}_{4}\right)$ boron groups, presented in all borate crystals.

Optical absorption spectra were registered at room and liquid nitrogen temperatures on a Carl Zeiss Jena (model Specord M-40) spectrophotometer. 
Photoluminescence spectra were measured in the $4.2 \div$ $300 \mathrm{~K}$ temperature range using equipment of the Institute of Low Temperatures and Structure Research of the Polish Academy of Sciences (Wrocław, Poland). Luminescence spectra were excited by an Ar laser operating at $\lambda=514.5 \mathrm{~nm}$. Emission spectra at room temperature were recorded with a Dongwoo (model DM 711) scanning monochromator having $750 \mathrm{~mm}$ focal length equipped with an InGaAs detector. Low temperature emission spectra were dispersed with a double grating monochromator (focal length - $1 \mathrm{~m}$ ) and detected by a photomultiplier with S-1 spectral response.

Luminescence decay curves were recorded with a Tektronix (model TDS 3052) digital oscilloscope. Excitation was provided by a continuum surelite I optical parametric oscillator (OPO) pumped by a third harmonic of an YAG: $\mathrm{Nd}^{3+}$ laser $(\lambda=355 \mathrm{~nm})$. For low temperature measurements the sample was mounted in an Oxford (model CF 2104) continuous flow liquid helium cryostat equipped with a temperature controller.

\section{Results and discussion}

\subsection{Optical spectra and luminescence kinetics of $\mathrm{Nd}^{3+}$ centres}

The Nd impurity in oxide crystals and glasses reveals as $\mathrm{Nd}^{3+}\left(4 f^{3}\right.$ - electron configuration, ${ }^{4} I_{9 / 2}$ - free ion ground state) and $\mathrm{Nd}^{2+}\left(4 f^{4},{ }^{5} I_{4}\right)$ ions with characteristic optical absorption, luminescence and EPR spectra. In the $\mathrm{Sr}_{4} \mathrm{~B}_{14} \mathrm{O}_{25}$ :Nd single crystal only $\mathrm{Nd}^{3+}$ optical and EPR spectra were observed [24]. Thus, the Nd impurity is incorporated into the $\mathrm{Sr}_{4} \mathrm{~B}_{14} \mathrm{O}_{25}$ crystal lattice as $\mathrm{Nd}^{3+}$ ions, exclusively, because characteristic optical spectra of $\mathrm{Nd}^{2+}$ ions were not registered.

Low symmetry (monoclinic) and anisotropy of the $\mathrm{Sr}_{4} \mathrm{~B}_{14} \mathrm{O}_{25}$ unit cell leads to anisotropy of the refractive index and other optical characteristics of these crystals, in particular optical absorption. Optical absorption spectra of the $\mathrm{Sr}_{4} \mathrm{~B}_{14} \mathrm{O}_{25}: \mathrm{Nd}$ single crystal in the $340 \div 1000 \mathrm{~nm}\left(10000 \div 30000 \mathrm{~cm}^{-1}\right)$ spectral range, registered at room temperature with using polarised light in the $\boldsymbol{E}\|a, \boldsymbol{E}\| b$, and $\boldsymbol{E} \| c$ crystallographic orientations, consist of several characteristic absorption bands with weakly-resolved structure that belong to $\mathrm{Nd}^{3+}$ ions (Fig. 1). The polarised optical absorption spectra show some differences in the lines intensities and their positions at different orientations (Fig. 1) which reflects low symmetry of $\mathrm{Nd}^{3+}$ centres in the $\mathrm{Sr}_{4} \mathrm{~B}_{14} \mathrm{O}_{25}$ lattice.

The linewidth and resolution of the $\mathrm{Nd}^{3+}$ absorption bands practically were not changed at lowering temperature up to liquid nitrogen which is an evidence of the inhomogeneous broadening related to disordering of the $\mathrm{Sr}_{4} \mathrm{~B}_{14} \mathrm{O}_{25}$ crystal structure. As a result, some observed complex and weakly-resolved $\mathrm{Nd}^{3+}$ bands can be assigned to groups of absorption transitions, as was shown in Fig. 1. In accordance with the $\mathrm{Nd}^{3+}$ energy levels diagram and referenced data $[25,26]$ all observed absorption bands were assigned to appropriate electronic $f-f$

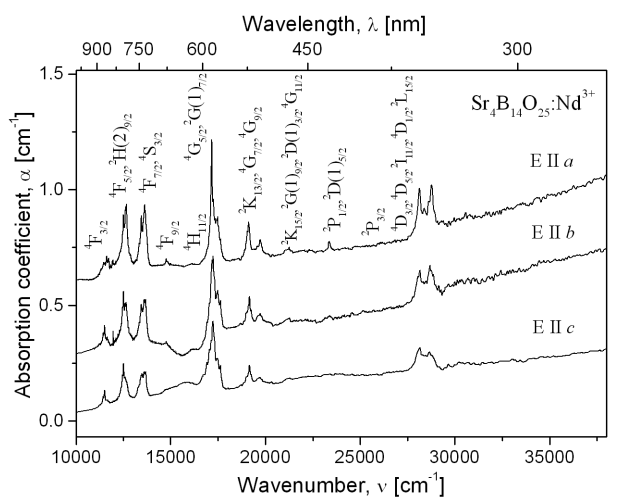

Fig. 1. Polarised optical absorption spectra of the $\mathrm{Sr}_{4} \mathrm{~B}_{14} \mathrm{O}_{25}: \mathrm{Nd}$ crystal, containing 0.2 wt.\% of $\mathrm{Nd}$ recorded at room temperature $(T=300 \mathrm{~K})$ in the $\boldsymbol{E}\|a(\mathrm{a}), \boldsymbol{E}\| b(\mathrm{~b})$, and $\boldsymbol{E} \| c(\mathrm{c})$ crystallographic orientations.

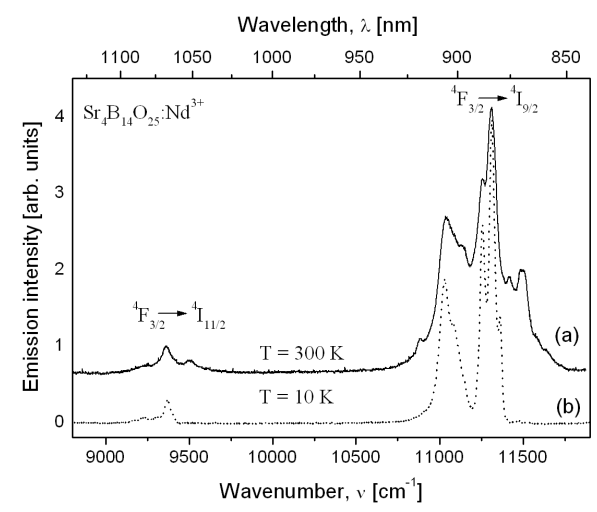

Fig. 2. Luminescence spectra of $\mathrm{Nd}^{3+}$ centres in the $\mathrm{Sr}_{4} \mathrm{~B}_{14} \mathrm{O}_{25}$ :Nd crystal containing 0.2 wt. $\%$ of Nd under excitation with Ar laser $\left(\lambda_{\text {exc }}=514.5 \mathrm{~nm}\right)$ recorded at $T=300 \mathrm{~K}(\mathrm{a})$ and $T=10 \mathrm{~K}(\mathrm{~b})$.

transitions from ${ }^{4} I_{9 / 2}$ ground state to following terms of excited states: $\left({ }^{4} D_{3 / 2},{ }^{4} D_{5 / 2},{ }^{2} I_{11 / 2},{ }^{4} D_{1 / 2},{ }^{2} L_{15 / 2}\right),{ }^{2} P_{3 / 2}$, $\left({ }^{2} P_{1 / 2},{ }^{2} D(1)_{5 / 2}\right),\left({ }^{2} K_{15 / 2},{ }^{2} G(1)_{9 / 2},{ }^{2} D(1)_{3 / 2},{ }^{4} G_{11 / 2}\right)$, $\left({ }^{2} K_{13 / 2},{ }^{4} G_{7 / 2},{ }^{4} G_{9 / 2}\right),\left({ }^{4} G_{5 / 2},{ }^{2} G(1)_{7 / 2}\right),{ }^{4} H_{11 / 2},{ }^{4} F_{9 / 2}$, $\left({ }^{4} F_{7 / 2},{ }^{4} S_{3 / 2}\right),\left({ }^{4} F_{5 / 2},{ }^{2} H(2)_{9 / 2}\right)$, and ${ }^{4} F_{3 / 2}$ (Fig. 1). In the luminescence excitation spectrum of $\mathrm{Nd}^{3+}$ centres at room temperature there were also observed several weakly-resolved and unresolved bands that correspond to optical absorption transitions. One can notice that the ${ }^{4} I_{9 / 2} \rightarrow{ }^{2} P_{3 / 2}$ and ${ }^{4} I_{9 / 2} \rightarrow{ }^{4} H_{11 / 2}$ transitions of $\mathrm{Nd}^{3+}$ centres only weakly reveal in the optical absorption (Fig. 1) and luminescence excitation spectra at all crystallographic orientations.

The $\mathrm{Nd}^{3+}$ emission spectra recorded at different temperatures under excitation with Ar laser $\left(\lambda_{\text {exc }}=\right.$ $514.5 \mathrm{~nm})$ in the absorption band, correspond to ${ }^{4} I_{9 / 2} \rightarrow$ $\left({ }^{2} K_{13 / 2},{ }^{4} G_{7 / 2},{ }^{4} G_{9 / 2}\right)$ transitions, and consist of two characteristic complex bands belonging to ${ }^{4} F_{3 / 2} \rightarrow{ }^{4} I_{9 / 2}$ and ${ }^{4} F_{3 / 2} \rightarrow{ }^{4} I_{11 / 2} f-f$ transitions (Fig. 2). The emis- 
sion band corresponding to ${ }^{4} F_{3 / 2} \rightarrow{ }^{4} I_{13 / 2}\left(\lambda_{\max } \cong\right.$ $1340 \mathrm{~nm}$ ) transition was not shown in Fig. 2, because luminescence spectra were registered in the $830 \div 1130 \mathrm{~nm}$ spectral range. At liquid helium temperatures better resolution of the ${ }^{4} F_{3 / 2} \rightarrow{ }^{4} I_{9 / 2}$ and ${ }^{4} F_{3 / 2} \rightarrow{ }^{4} I_{11 / 2}$ emission bands was observed (Fig. 2, spectrum b) that is an evidence of homogeneous broadening. The inhomogeneous broadening also is characteristic for luminescence spectra of the $\mathrm{Sr}_{4} \mathrm{~B}_{14} \mathrm{O}_{25}$ : Nd crystal, because even at liquid helium temperatures the $\mathrm{Nd}^{3+}$ emission bands is not satisfactorily resolved (Fig. 2). The inhomogeneous broadening is caused by disordering of the local oxygen neighbourhood around the $\mathrm{Nd}^{3+}$ centres in the $\mathrm{Sr}_{4} \mathrm{~B}_{14} \mathrm{O}_{25}$ lattice. The emission spectrum at low temperatures shows only one type of luminescence centres in the $\mathrm{Sr}_{4} \mathrm{~B}_{14} \mathrm{O}_{25}$ crystal lattice, because the complex band corresponds to ${ }^{4} F_{3 / 2} \rightarrow{ }^{4} I_{9 / 2}$ transition, is split to five relatively broad components that are characteristic for $\mathrm{Nd}^{3+}$ centres, localised in the single site of crystal lattice with low symmetry.

The observed optical absorption and luminescence spectra of $\mathrm{Nd}^{3+}$ ions in the $\mathrm{Sr}_{4} \mathrm{~B}_{14} \mathrm{O}_{25}: \mathrm{Nd}^{3+}$ single crystals weakly depend on temperature in the $4.2 \div 300 \mathrm{~K}$ range and are closely similar to $\mathrm{Nd}^{3+}$ optical spectra in other disordered oxide crystals and glasses [15, 27, 28], in particular to borate glasses with the same $\left(4 \mathrm{SrO}-7 \mathrm{~B}_{2} \mathrm{O}_{3}\right)$ composition [22].

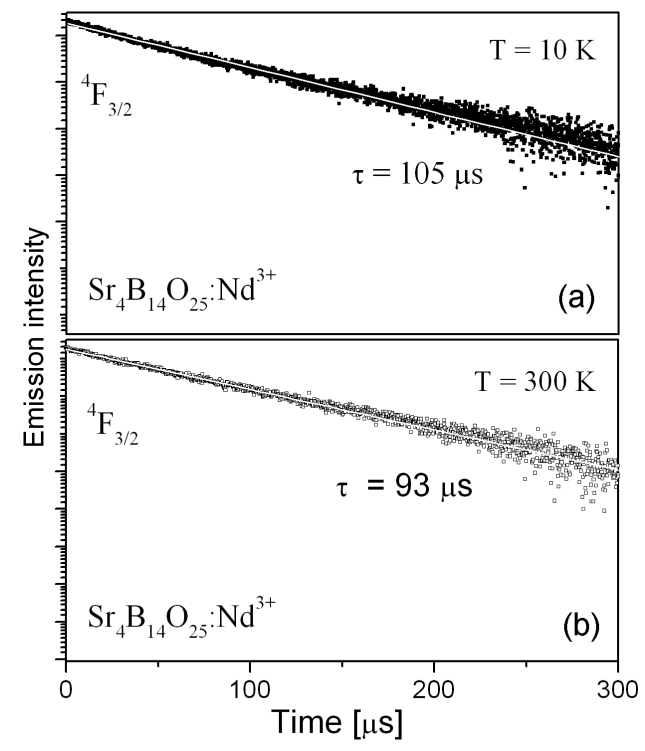

Fig. 3. Luminescence decay curves of $\mathrm{Nd}^{3+}$ centres for ${ }^{4} F_{3 / 2} \rightarrow{ }^{4} I_{11 / 2}$ transition $\left(\lambda_{\max }=1065 \mathrm{~nm}\right)$, registered at $T=10 \mathrm{~K}(\mathrm{a})$ and $T=300 \mathrm{~K}(\mathrm{~b})$ in the $\mathrm{Sr}_{4} \mathrm{~B}_{14} \mathrm{O}_{25}: \mathrm{Nd}$ crystal containing 0.2 wt.\% of Nd. White solid lines results of the single exponential fit.

Luminescence decay curves for ${ }^{4} F_{3 / 2} \rightarrow{ }^{4} I_{11 / 2}$ transition $\left(\lambda_{\max } \cong 1065 \mathrm{~nm}\right)$ of the $\mathrm{Nd}^{3+}$ centres in the $\mathrm{Sr}_{4} \mathrm{~B}_{14} \mathrm{O}_{25}: \mathrm{Nd}$ crystal at temperatures 10 and $300 \mathrm{~K}$ are presented in Fig. 3a and b, respectively. The observed curves can be satisfactorily fitted by single expo- nential decay with lifetimes $\tau=105 \mu \mathrm{s}$ (at $T=10 \mathrm{~K}$ ) and $\tau=93 \mu \mathrm{s}$ (at $T=300 \mathrm{~K}$ ). One can notice that in the $\mathrm{Ca}_{3} \mathrm{Ga}_{2} \mathrm{Ge}_{3} \mathrm{O}_{12}: \mathrm{Nd}^{3+}$ laser garnet containing 0.8 at. $\%$ of $\mathrm{Nd}_{2} \mathrm{O}_{3}$ the $\mathrm{Nd}^{3+}$ centres in the ${ }^{4} F_{3 / 2}$ level are characterised by approximately single-exponential decay with lifetime $\tau=(210 \pm 10) \mu \mathrm{s}$ at $T=4.2$ and $77 \mathrm{~K}[29]$. In silicate-phosphate glasses with $56 \mathrm{CaO}-$ $35 \mathrm{SiO}_{2}-9 \mathrm{P}_{2} \mathrm{O}_{5}$ composition the $\mathrm{Nd}^{3+}$ lifetime in the ${ }^{4} F_{3 / 2}$ level $\tau=330 \mu$ s and is independent of temperature in the $10 \div 300 \mathrm{~K}$ range for sample containing $\approx 0.07 \mathrm{wt} . \%$ of $\mathrm{Nd}_{2} \mathrm{O}_{3}$, whereas for samples containing $1 \div 4$ wt. $\%$ of $\mathrm{Nd}_{2} \mathrm{O}_{3} \tau \cong 295 \mu$ s at $T=10 K$ and $\tau \cong 245 \mu$ s at $T=300 \mathrm{~K}$ [30]. The very short lifetime values for $\mathrm{Nd}^{3+}$ centres in the $\mathrm{Sr}_{4} \mathrm{~B}_{14} \mathrm{O}_{25}: \mathrm{Nd}$ crystal are not related to concentration decay, because the $\mathrm{Nd}$ content (0.2 wt.\%) in this crystal is relatively low. In our opinion the obtained short lifetime values indicate strong interaction of the $\mathrm{Nd}^{3+}$ centres with lattice vibration modes (phonons).

\subsection{The Judd-Ofelt analysis and spectroscopic parameters of $\mathrm{Nd}^{3+}$ centres}

Transition energies and relative intensities of the $\mathrm{Nd}^{3+}$ absorption bands in the $\mathrm{Sr}_{4} \mathrm{~B}_{14} \mathrm{O}_{25}$ : Nd single crystal were analysed on the basis of Judd-Ofelt theory [31, 32]. It is invaluable tool in estimating relaxation rates of excited levels. At present this method is widely and commonly used to assess the laser potential of rare-earth doped materials. In view of the Judd-Ofelt procedures the spectroscopic properties of rare-earth doped materials may be determined by using three phenomenological parameters $\Omega_{t}(t=2,4,6)$. The least squares fit between the theoretical $\left(P_{\text {theor }}\right)$ and experimental $\left(P_{\text {exp }}\right)$ oscillator strengths derived from absorption spectrum is employed to obtain the $\Omega_{t}$ parameters. Utilising this procedure we determined experimental oscillator strengths for transitions from the ground ${ }^{4} I_{9 / 2}$ multiplet to excited multiplets of $\mathrm{Nd}^{3+}$ by numerical integration of absorption bands according to following equation:

$$
P_{\exp }=\frac{4.33 \times 10^{-9}}{d C} \int \alpha(\nu) \mathrm{d} \nu .
$$

The $\int \alpha(\nu) \mathrm{d} \nu$ means an integrated area under individual absorption band expressed in terms of absorption coefficient $\alpha$ at a wave number $\nu, d$ is the crystal thickness in $\mathrm{cm}$, and $C$ denotes a concentration of an optically-active impurity expressed in $\mathrm{mol} \mathrm{cm}^{-3}$. Whereas the expression for theoretical oscillator strength was constructed and equated to experimental oscillator strength $P_{\text {exp }}$ to acquire some equations of the form

$$
\begin{gathered}
P_{\text {theor }}=\frac{8 \pi^{2} m c}{3 h \lambda(2 J+1)} \frac{\left(n^{2}+2\right)^{2}}{9 n} \sum_{t=2,4,6} \Omega_{t} \\
\times\left|\left\langle f^{\mathrm{N}}[L, S] J\left\|U^{(t)}\right\| f^{\mathrm{N}}\left[L^{\prime}, S^{\prime}\right] J^{\prime}\right\rangle\right|^{2},
\end{gathered}
$$

where $\lambda$ is a mean wavelength of the transition, $n$ is a refractive index of the host. The $\left.U^{(} t\right)$ represent matrix elements of unit tensor $U^{t}$. Symbols $m, c$, and $h$ denote electron mass, the light velocity and the Planck constant, respectively. The fitting procedure of observed 
transitions of $\mathrm{Nd}^{3+}$ centres in the $\mathrm{Sr}_{4} \mathrm{~B}_{14} \mathrm{O}_{25}$ :Nd crystal created the following phenomenological intensity parameters: $\Omega_{2}=1.59 \times 10^{-20}, \Omega_{4}=2.06 \times 10^{-20}, \Omega_{6}=$ $2.28 \times 10^{-20}$ (Table I). For comparison in Table I there are presented experimental oscillator strengths $\left(P_{\exp }\right)$ calculated from average energies $(\bar{E})$ of the absorption bands maxima according to relation given in [29]. Differences between theoretical $\left(P_{\text {theor }}\right)$ and experimental $\left(P_{\exp }\right)$ oscillator strengths for all observed $\mathrm{Nd}^{3+}$ absorption bands in the $\mathrm{Sr}_{4} \mathrm{~B}_{14} \mathrm{O}_{25}$ :Nd crystal are negligible (Table I) that shows good correlation of the experimental data with the Judd-Ofelt calculations.

TABLE I

Results of the Judd-Ofelt analysis for $\mathrm{Nd}^{3+}$ centres in the $\mathrm{Sr}_{4} \mathrm{~B}_{14} \mathrm{O}_{25}$ : Nd crystal.

\begin{tabular}{|c|c|c|c|c|}
\hline \multirow{2}{*}{$\begin{array}{l}\text { Absorption transitions } \\
\qquad{ }^{4} I_{9 / 2} \rightarrow\end{array}$} & \multicolumn{4}{|c|}{$\begin{array}{l}\text { Oscillator strength } \\
\qquad P \times 10^{6}\end{array}$} \\
\hline & $(\boldsymbol{E} \| a)$ & $(\boldsymbol{E} \| b)$ & $(\boldsymbol{E} \| c)$ & $P_{\text {mean }}$ \\
\hline${ }^{4} F_{3 / 2}$ & 0.88 & 0.80 & 0.68 & 0.79 \\
\hline${ }^{4} F_{5 / 2}+{ }^{2} H(2)_{9 / 2}$ & 4.30 & 3.16 & 2.27 & 3.24 \\
\hline${ }^{4} F_{7 / 2}+{ }^{4} S_{3 / 2}$ & 4.55 & 3.58 & 2.25 & 3.46 \\
\hline${ }^{4} G_{5 / 2}+{ }^{2} G(1)_{7 / 2}$ & 8.26 & 8.77 & 7.21 & 8.08 \\
\hline${ }^{2} K_{13 / 2}+{ }^{4} G_{7 / 2}+{ }^{4} G_{9 / 2}$ & 3.96 & 3.30 & 2.29 & 3.18 \\
\hline${ }^{4} D_{3 / 2}+{ }^{4} D_{5 / 2}+{ }^{2} I_{11 / 2}+{ }^{4} D_{1 / 2}+{ }^{2} L_{15 / 2}$ & 6.89 & 5.90 & 4.58 & 5.79 \\
\hline $\begin{array}{l}\text { Absorption transitions } \\
\qquad{ }^{4} I_{9 / 2} \rightarrow\end{array}$ & $\begin{array}{l}\text { Energy } \\
E\left[\mathrm{~cm}^{-1}\right]\end{array}$ & $\begin{array}{c}\text { Oscillator } \\
\text { strength } \\
P_{\exp } \\
\end{array}$ & $\begin{array}{c}\text { Oscillator } \\
\text { strength } \\
P_{\text {theor }}\end{array}$ & Difference \\
\hline${ }^{4} F_{3 / 2}$ & 11538 & $7.90 \times 10^{-7}$ & $7.18 \times 10^{-7}$ & $0.59 \times 10^{-7}$ \\
\hline${ }^{4} F_{5 / 2}+{ }^{2} H(2)_{9 / 2}$ & 12527 & $3.24 \times 10^{-6}$ & $3.39 \times 10^{-6}$ & $0.15 \times 10^{-6}$ \\
\hline${ }^{4} F_{7 / 2}+{ }^{4} S_{3 / 2}$ & 13517 & $3.46 \times 10^{-6}$ & $3.46 \times 10^{-6}$ & 0.00 \\
\hline${ }^{4} G_{5 / 2}+{ }^{2} G(1)_{7 / 2}$ & 17227 & $8.08 \times 10^{-6}$ & $8.08 \times 10^{-6}$ & 0.00 \\
\hline${ }^{2} K_{13 / 2}+{ }^{4} G_{7 / 2}+{ }^{4} G_{9 / 2}$ & 19442 & $3.18 \times 10^{-6}$ & $2.64 \times 10^{-6}$ & $0.54 \times 10^{-6}$ \\
\hline${ }^{4} D_{3 / 2}+{ }^{4} D_{5 / 2}+{ }^{2} I_{11 / 2}+{ }^{4} D_{1 / 2}+{ }^{2} L_{15 / 2}$ & 28322 & $5.79 \times 10^{-6}$ & $5.79 \times 10^{-6}$ & 0.00 \\
\hline
\end{tabular}

At the consequence the $\Omega_{t}$ parameters were employed to found the radiative transition rates $W_{\mathrm{r}}$ from the ${ }^{4} F_{3 / 2}$ level to lower lying neodymium manifolds, according to formula

$$
\begin{array}{r}
W_{\mathrm{r}}=\frac{64 \pi^{4} e^{2}}{3 h(2 J+1) \lambda^{3}} \frac{n\left(n^{2}+2\right)^{2}}{9} \\
\times \sum_{t=2,4,6} \Omega_{t}\left|\left\langle b J^{\prime}\left\|U^{(t)}\right\| a J\right\rangle\right|^{2} .
\end{array}
$$

Luminescence branching ratios $\beta$ for ${ }^{4} F_{3 / 2} \rightarrow{ }^{4} I_{9 / 2}$, ${ }^{4} \mathrm{~F}_{3 / 2} \rightarrow{ }^{4} I_{11 / 2},{ }^{4} F_{3 / 2} \rightarrow{ }^{4} I_{13 / 2}$, and ${ }^{4} F_{3 / 2} \rightarrow{ }^{4} I_{15 / 2}$ electric dipole transitions were next estimated using the relation

$$
\beta=\frac{W_{\mathrm{r}}}{\sum_{j} W_{\mathrm{r}}} .
$$

The inverse of the rate sum of radiative transition from the given ${ }^{4} F_{3 / 2}$ excited multiplets to all terminal multiplet is commonly denoted as radiative lifetime $\tau_{\mathrm{r}}$ of this multiplet
TABLE II

Calculated rates of the spontaneous electric dipole transitions $\left(W_{\mathrm{r}}\right)$, branching ratios $(\beta)$, and radiative lifetime $\left(\tau_{\text {rad }}\right)$ for emission from the ${ }^{4} F_{3 / 2}$ level of $\mathrm{Nd}^{3+}$ centres in the $\mathrm{Sr}_{4} \mathrm{~B}_{14} \mathrm{O}_{25}: \mathrm{Nd}$ crystal.

\begin{tabular}{c|c|c|c}
\hline $\begin{array}{c}\text { Emission transitions } \\
{ }^{4} F_{3 / 2} \rightarrow\end{array}$ & $\begin{array}{c}\text { Energy of transitions } \\
E\left[\mathrm{~cm}^{-1}\right]\end{array}$ & $W_{\mathrm{r}}\left[\mathrm{s}^{-1}\right]$ & $\beta$ \\
\hline${ }^{4} I_{9 / 2}$ & 11156 & 745 & 0.2468 \\
${ }^{4} I_{11 / 2}$ & 9042 & 1928 & 0.6382 \\
${ }^{4} I_{13 / 2}$ & 7058 & 336 & 0.1112 \\
${ }^{4} I_{15 / 2}$ & 5008 & 12 & 0.0038 \\
\hline$\sum W_{\mathrm{r}}=3021 \mathrm{~s}^{-1}$, & $\tau_{\text {rad }}\left({ }^{4} F_{3 / 2}\right)=331 \mu \mathrm{s}$ & \\
$\tau_{\mathrm{r}}=\frac{1}{\sum_{j} W_{\mathrm{r}}}$.
\end{tabular}

Results of the calculations performed for the systems under study are gathered in Table II. It was found from these calculations that the majority of the ${ }^{4} F_{3 / 2}$ emission of $\mathrm{Nd}^{3+}$ is transferred to ${ }^{4} I_{11 / 2}(63 \%)$ and ${ }^{4} I_{9 / 2}$ 
$(11 \%)$ states. It is inferred thus that the ${ }^{4} F_{3 / 2} \rightarrow{ }^{4} I_{11 / 2}$ and ${ }^{4} F_{3 / 2} \rightarrow{ }^{4} I_{9 / 2}$ channels may be considered for potential laser generation. On the other hand, the unfavourable feature of the $\mathrm{Sr}_{4} \mathrm{~B}_{14} \mathrm{O}_{25}$ : Nd system is relatively low quantum efficiency of the spontaneous emission from the ${ }^{4} F_{3 / 2}$ metastable level of $\mathrm{Nd}^{3+}$ centres in the $\mathrm{Sr}_{4} \mathrm{~B}_{14} \mathrm{O}_{25}: \mathrm{Nd}$ crystal (Nd content 0.2 wt.\%) determined as $\eta=\tau_{\text {exp }} / \tau_{\text {rad }} \cong 30 \%$. The inefficient value of the radiative properties of the ${ }^{4} F_{3 / 2} \mathrm{Nd}^{3+}$ luminescence is frequently observed in borate materials owing to great cut-off frequency related to energy of phonons, around up to $1400 \mathrm{~cm}^{-1}$. In view of the high frequencies of oscillations in borate system, less than four phonons are required to bridging of the energy gap between the emitting ${ }^{3} F_{4}$ level and ${ }^{4} I_{15 / 2}$ state of neodymium that brings about the effective multiphonon relaxation process. For comparison it was documented in [33] that the assessed radiative quantum efficiency for neodymium doped $\mathrm{Na}_{2} \mathrm{O}-\mathrm{Al}_{2} \mathrm{O}_{3}-\mathrm{B}_{2} \mathrm{O}_{3}$ borate glass is equal to $20 \%$. The obtained value is considerably lower than that in the $\mathrm{Y}_{3} \mathrm{Al}_{5} \mathrm{O}_{12}: \mathrm{Nd}^{3+}[11]$ and $\mathrm{Ca}_{3} \mathrm{Ga}_{2} \mathrm{Ge}_{3} \mathrm{O}_{12}: \mathrm{Nd}^{3+}$ [29] laser crystals $(\eta \cong 97 \%)$, in phosphate $(\eta \cong 80 \%)$ [12] laser glasses as well as in $\mathrm{Ca}_{3} \mathrm{Ga}_{2} \mathrm{Ge}_{3} \mathrm{O}_{12}: \mathrm{Nd}^{3+}(\eta \cong 75 \%)$ [34] and fluoroborophosphate $(\eta=59 \div 65 \%)$ [35] glasses. Thus, the $\mathrm{Sr}_{4} \mathrm{~B}_{14} \mathrm{O}_{25}: \mathrm{Nd}^{3+}$ crystals cannot be considered as effective active media for lasers $\left({ }^{4} F_{3 / 2} \rightarrow{ }^{4} I_{11 / 2}\right.$ channel, $\left.\lambda_{\max } \cong 1065 \mathrm{~nm}\right)$, but represents very interesting objects for investigation of the local structure for $\mathrm{Nd}^{3+}$ centres.

\subsection{Local structure of the $\mathrm{Nd}^{3+}$ centres in crystal and glass with the $\mathrm{Sr}_{4} \mathrm{~B}_{14} \mathrm{O}_{25}$ composition}

Let us consider the incorporation peculiarities and local structure of the $\mathrm{Nd}^{3+}$ centres in the $\mathrm{Sr}_{4} \mathrm{~B}_{14} \mathrm{O}_{25}: \mathrm{Nd}$ crystal and corresponding glass with the same (4SrO$\left.7 \mathrm{~B}_{2} \mathrm{O}_{3}\right)$ composition. On the basis of X-ray diffraction and crystallographic data we suggest that the $\mathrm{Nd}^{3+}$ ions in the $\mathrm{Sr}_{4} \mathrm{~B}_{14} \mathrm{O}_{25}$ crystal occupy $\mathrm{Sr}$ sites (the $\mathrm{Sr}^{2+}$ and $\mathrm{Nd}^{3+}$ ionic radii are closely similar and equal to 1.26 and $1.15 \AA$, respectively). According to [20, 21, 23] four $\mathrm{Sr}$ sites in the $\mathrm{Sr}_{4} \mathrm{~B}_{14} \mathrm{O}_{25}$ lattice are characterised by coordination number to oxygen $N=6 \div 7$ with positional disordering in the first (oxygen) coordination sphere. The corresponding glass with the $4 \mathrm{SrO}-7 \mathrm{~B}_{2} \mathrm{O}_{3}$ composition is characterised by positional disordering of the atomic local structure and continual disturbance of the short-range order that destroys middle- and long-range order [36].

The presented above results of optical spectroscopy and luminescence kinetics analysis show that in the crystal with $\mathrm{Sr}_{4} \mathrm{~B}_{14} \mathrm{O}_{25}$ composition there is observed only one type of $\mathrm{Nd}^{3+}$ centres with local environment consisting of statistically-distributed $\mathrm{O}^{2-}$ anions with different structural parameters (interatomic distances and coordination numbers). The $\mathrm{Nd}^{3+}$ luminescence centres in the Sr sites of $\mathrm{Sr}_{4} \mathrm{~B}_{14} \mathrm{O}_{25}$ crystal lattice are characterised by slightly different spectroscopic parameters that reveals in the inhomogeneous broadening of spectral lines. Optical spectroscopy of the glass with the same $\left(\mathrm{Sr}_{4} \mathrm{~B}_{14} \mathrm{O}_{25}: \mathrm{Nd}\right)$ composition [22] also shows one type of $\mathrm{Nd}^{3+}$ centres, localised in the $\mathrm{Sr}$ sites of the glass network with different $\mathrm{Nd}^{3+}-\mathrm{O}^{2-}$ distances (positional disorder) in the first coordination shell and continual disturbance of the short-range order. Therefore, the $\mathrm{Nd}^{3+}$ optical spectra in the glass with $\mathrm{Sr}_{3} \mathrm{~B}_{14} \mathrm{O}_{25}$ : $\mathrm{Nd}$ composition are characterised by strong inhomogeneous broadening of spectral lines caused by broad distribution of spectroscopic parameters. On the basis of published data for $\mathrm{Nd}^{3+}$ ions in other oxide crystals and glasses with the same composition $[34,36,37]$ we can suppose that the local structure of $\mathrm{Nd}^{3+}$ centres in the glass and crystal with $\mathrm{Sr}_{3} \mathrm{~B}_{14} \mathrm{O}_{25}$ composition is quite similar and characterised by positionally-disordered oxygen local environments. This suggestion needs confirmation by extended $\mathrm{X}$-ray absorption fine structure (EXAFS) investigation of the $\mathrm{Nd}$ impurity $L_{3}$-edge [36] in the crystal and glass with the $\mathrm{Sr}_{3} \mathrm{~B}_{14} \mathrm{O}_{25}$ : Nd composition.

\section{Conclusions}

The $\mathrm{Sr}_{4} \mathrm{~B}_{14} \mathrm{O}_{25}$ :Nd single crystals of high optical quality and chemical purity were synthesised in air by modified Czochralski method according to developed by authors technology. On the basis of obtained and referenced data analysis the following was shown:

1. The neodymium impurity is incorporated into the $\mathrm{Sr}_{4} \mathrm{~B}_{14} \mathrm{O}_{25}: \mathrm{Nd}$ crystal lattice as $\mathrm{Nd}^{3+}\left(4 f^{3},{ }^{4} I_{9 / 2}\right)$ ions, exclusively, and formed the $\mathrm{Nd}^{3+}$ luminescence centres with characteristic optical absorption and luminescence spectra.

2. All observed UV, visible, and IR transitions of the $\mathrm{Nd}^{3+}$ centres in optical absorption and luminescence spectra have been identified. Optical spectra of $\mathrm{Nd}^{3+}$ centres in the $\mathrm{Sr}_{4} \mathrm{~B}_{14} \mathrm{O}_{25}$ : Nd single crystal are quite similar to $\mathrm{Nd}^{3+}$ optical spectra in the corresponding glasses with the same composition and other disordered oxide compounds and are characterised by inhomogeneous broadening of spectral lines.

3. The luminescence kinetics of the $\mathrm{Nd}^{3+}$ centres for ${ }^{4} F_{3 / 2} \rightarrow{ }^{4} I_{11 / 2}$ transition $\left(\lambda_{\max } \cong 1065 \mathrm{~nm}\right)$ in the samples containing $0.2 \mathrm{wt} . \%$ of $\mathrm{Nd}$ is satisfactorily described by single exponential decay with lifetimes $\tau=105 \mu \mathrm{s}$ and $93 \mu \mathrm{s}$, obtained at $T=10$ and $300 \mathrm{~K}$, respectively.

4. The optical spectra of the $\mathrm{Nd}^{3+}$ centres were analysed and described in the framework of Judd-Ofelt theory. The oscillator strengths, phenomenological Judd-Ofelt intensity parameters and parameters relevance to laser applications (radiative transition rates, branching ratios and radiative lifetime) for $\mathrm{Nd}^{3+}$ centres in the $\mathrm{Sr}_{4} \mathrm{~B}_{14} \mathrm{O}_{25}$ : $\mathrm{Nd}$ single crystal have been calculated and analysed. In particular, it was shown that the investigated $\mathrm{Sr}_{4} \mathrm{~B}_{14} \mathrm{O}_{25}: \mathrm{Nd}$ 
single crystal is not perspective material for lasers, operating in the infrared spectral region, because quantum efficiency of the $F_{3 / 2} \rightarrow{ }^{4} I_{11 / 2}$ channel is low $(\eta \cong 30 \%)$.

5. The $\mathrm{Nd}^{3+}$ centres are localised in the $\mathrm{Sr}$ positions, coordinated by positionally-disordered $\mathrm{O}^{2-}$ anions in the $\mathrm{Sr}_{4} \mathrm{~B}_{14} \mathrm{O}_{25}: \mathrm{Nd}$ crystal lattice that is also characteristic for corresponding glass with the same composition and other disordered borate compounds. The multisite $\mathrm{Nd}^{3+}$ luminescence in the $\mathrm{Sr}_{4} \mathrm{~B}_{14} \mathrm{O}_{25}$ crystals is related to presence of four Sr positions in their lattice with close coordination numbers $(N=6 \div 7)$ and different statistically-distributed $\mathrm{Nd}^{3+}-\mathrm{O}^{2-}$ distances which leads to distribution of $\mathrm{Nd}^{3+}$ spectroscopic parameters and reveals in the inhomogeneous broadening of spectral lines.

\section{Acknowledgments}

This work was supported by the Ministry of Education and Science of Ukraine (research project No. 0109U001063) and University of Zielona Góra (Poland).

\section{References}

[1] Y.U. Oseledchik, A.L. Prosvirnin, V.V. Starshenko, V.V. Osadchuk, A.I. Pisarevskiy, S.P. Belokrys, A.S. Korol, N.V. Svitanko, A.F. Selevich, S.A. Krikunov, J. Cryst. Growth 135, 373 (1994).

[2] Yu.S. Oseledchik, A.L. Prosvirnin, A.I. Pisarevskiy, Opt. Mater. 4, 669 (1995).

[3] F. Pan', G. Shen, R. Wang, X. Wang, D. Shen, J. Cryst. Growth 241, 108 (2002).

[4] M. Santiago, A. Lavat, E. Caselli, M. Lester, L.J. Perisinotti, A.K. de Figuereido, F. Spano, F. Ortega, Phys. Status Solidi A 167, 233 (1998).

[5] M.F. Dubovik, T.I. Korshikova, Yu.S. Oseledchik, S.V. Parkhomenko, A.L. Prosvirnin, N.V. Svitanko, A.V. Tolmachev, R.P. Yavetsky, Funct. Mater. 12, 685 (2005).

[6] Z. Pei, Q. Su, S. Li, J. Lumin. 50, 123 (1991).

[7] Z. Pei, Q. Su, J. Alloys Comp. 198, 51 (1993).

[8] W.J. Schipper, A. Meijerink, G. Blasse, J. Lumin. 62, 55 (1994).

[9] Q. Zeng, Z. Pei, S. Wang, Q. Su, J. Phys. Chem. Solids 60, 515 (1999).

[10] A. Lavat, C. Graselli, M. Santiago, J. Pomarico, E. Caselli, Cryst. Res. Technol. 39, 840 (2004).

[11] A.A. Kaminskii, B.M. Antipenko, Multi-level Operating Schemes of Crystalline Lasers, Nauka, Moskva 1989 (in Russian).

[12] D.C. Brown, High-Peak-Power Nd:Glass Laser Systems, Springer-Verlag, Berlin 1981.

[13] W. Ryba-Romanowski, Acta Phys. Pol. A 84, 945 (1993).

[14] D.K. Sardar, S. Vizcarra, M.A. Islam, T.H. Allik, E.J. Sharp, A.A. Pinto, Opt. Mater. 3, 257 (1994).

[15] A.A. Kaminskii, E.L. Belokoneva, B.V. Mill, Yu.V. Pisarevskii, S.E. Sarkisov, I.M. Silvestrova, A.V. Butashin, G.G. Khodzhabagyan, Phys. Status Solidi A 86, 345 (1984).
[16] Y. Guyot, L.E. Bausá, E. Camarillo, J. García Solé, I. Vergara, A. Monteil, R. Moncorgé, J. Appl. Phys. 72, 5876 (1992).

[17] Yu.S. Oseledchik, A.L. Prosvirnin, D.P. Kudryavtcev, N.V. Svitanko, Patent of Ukraine, No. UA 49341 A, September 16, 2002, Bull. No. 6.

[18] Yu.S. Oseledchik, A.L. Prosvirnin, D.P. Kudryavtcev, N.V. Svitanko, Patent of Ukraine, No. UA 61223 A, November 17, 2003, Bull. No. 11.

[19] D.P. Kudryavtcev, Yu.S. Oseledchik, A.L. Prosvirnin, N.V.J. Svitanko, Cryst. Growth 254, 456 (2003).

[20] D.P. Kudrjavtcev, Yu.S. Oseledchik, A.L. Prosvirnin, N.V. Svitanko, V.V. Petrov, Ukr. J. Phys. Opt. 3, 155 (2002).

[21] D.P. Kudrjavtsev, Yu.S. Oseledchik, A.L. Prosvirnin, N.V. Svitanko, Ukr. J. Phys. 48, 11 (2003).

[22] D.P. Kudryavtcev, Yu.S. Oseledchik, A.L. Prosvirnin, N.V. Svitanko, Ukr. J. Phys. Opt. 4, 83 (2003).

[23] A.E. Lapshin, E.O. Litovchik, I.G. Polyakova, Yu.F. Shepelev, Russ. J. Inorg. Chem. 52, 839 (2007).

[24] B.V. Padlyak, W. Ryba-Romanowski, R. Lisiecki, Yu.S. Oseledchik, A.L. Prosvirnin, D.P. Kudryavtcev, N.V. Svitanko, in: 5th Int. Workshop on Functional and Nanostructured Materials, Abstract Book, Ed. J. Rybicki, TASK Publ., Gdańsk 2008, p. 67.

[25] W.T. Carnall, P.R. Fields, K. Rajnak, J. Chem. Phys. 49, 4424 (1968).

[26] B. Henderson, R.H. Bartram, Crystal-Field Engineering of Solid-State Lasers Materials, Cambridge University Press, Cambridge 2000.

[27] L.C. Courrol, L.R.P. Kassab, V.D.D. Cacho, S.H. Tatumi, N.U. Wetter, J. Lumin. 102-103, 101 (2003).

[28] F.F. Sene, J.R. Martinelli, L. Gomes, J. Non-Cryst. Solids 348, 63 (2004).

[29] F. Ramos, H. Loro, E. Camarillo, J. García-Solé, A.A. Kaminskii, U.G. Caldiño, Opt. Mater. 12, 93 (1999).

[30] G.A. Kumar, E. de la Rosa-Cruz, A. Martinez, N.V. Unnikrishnan, K. Ueda, J. Phys. Chem. Solids 64, 69 (2003).

[31] B.R. Judd, Phys. Rev. 127, 750 (1962).

[32] G.S. Ofelt, J. Chem. Phys. 37, 511 (1962).

[33] V. Mehta, G. Aka, A.L. Dawar, A. Mansingh, Opt. Mater. 12, 53 (1999).

[34] B. Padlyak, W. Ryba-Romanowski, R. Lisiecki, Opt. Appl. XXXVIII, 189 (2008).

[35] F. D'Acapito, S. Mobilio, P. Gastaldo, D. Barbier, L.F. Santos, O. Martins, R.M. Almeida, J. Non-Cryst. Solids 293-295, 118 (2001).

[36] A. Witkowska, B. Padlyak, J. Rybicki, J. Non-Cryst. Solids 352, 4346 (2006).

[37] A. Witkowska, B. Padlyak, J. Rybicki, Opt. Mater. 30, 699 (2008). 